\title{
Desenvolvimento da competência para a prescrição de medicamentos na Atenção Básica na formação do enfermeiro
}

\author{
Development of competence for the prescription of drugs in Primary Care in nursing education \\ Desarrollo de la competencia para la prescripción de medicamentos en Atención Primaria en la \\ educación de enfermería
}

Recebido: 31/08/2021 | Revisado: 09/09/2021 | Aceito: 13/09/2021 | Publicado: 15/09/2021

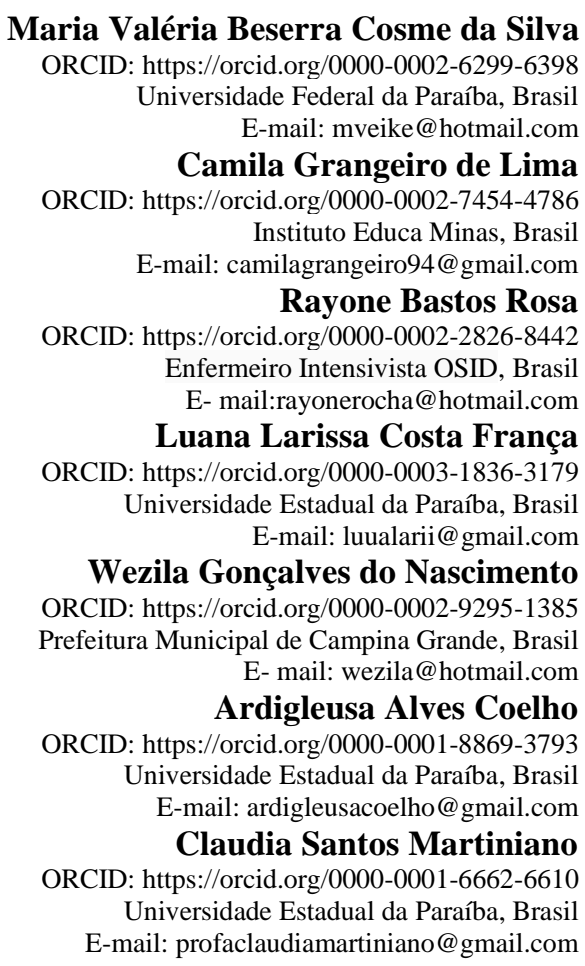

\begin{abstract}
Resumo
Objetivou-se com essa pesquisa investigar a existência de previsão para desenvolvimento de competências para prescrição de medicamentos por enfermeiros nos Projetos Pedagógicos de Curso (PPC) do curso de Enfermagem das Instituições de Ensino Superior da rede pública e privada de Campina Grande- PB. Propõe-se um estudo qualitativo com abordagem descritiva e documental. $\mathrm{O}$ estudo foi realizado no Município de Campina Grande- $\mathrm{PB}$, junto às instituições de ensino superior que possuem em sua matriz de ensino o curso de Graduação em Enfermagem. A coleta se deu por meio duas etapas operacionais: análise de todos os PPC, a segunda foi uma entrevista semiestruturada, utilizando um roteiro previamente estabelecido e flexível com os coordenadores dos cursos. Os PPC das instituições investigadas não abordam conteúdos/componentes curriculares para desenvolver no estudante competências para a prescrição de medicamentos e que as instituições enfrentam desafios em readequar os projetos pedagógicos pós redemocratização do ensino. Faz-se necessário que os coordenadores dos cursos e os docentes desenvolvam meios para readequação do PPC de acordo com o que preconiza o SUS para promover nos alunos uma visão crítica e reflexiva voltada para o seu campo de atuação.
\end{abstract}

Palavras-chave: Atenção Primária à Saúde; Ensino de enfermagem; Prescrição de medicamentos por enfermeiros.

\section{Abstract}

The objective of this research was to investigate the existence of a forecast for the development of competences for the prescription of medicines by nurses in the Pedagogical Course Projects (PPC) of the Nursing course of Higher Education Institutions in the public and private network of Campina Grande-PB. A qualitative study with a descriptive and documentary approach is proposed. The study was carried out in the city of Campina Grande-PB, together with higher education institutions that have the Nursing Undergraduate course in their teaching matrix. The collection took place 
through two operational stages: analysis of all PPC, the second was a semi-structured interview, using a previously established and flexible script with the course coordinators. The PPCs of the investigated institutions do not address curricular content/components to develop in the student competences for the prescription of medicines and that institutions face challenges in readjusting the pedagogical projects after the redemocratization of teaching. It is necessary that course coordinators and professors develop means to readjust the PPC in accordance with what the SUS advocates to promote in students a critical and reflective view focused on their field of action.

Keywords: Primary Health Care; Nursing education; Prescription of medicines by nurses.

\section{Resumen}

El objetivo de esta investigación fue investigar la existencia de una previsión para el desarrollo de competencias para la prescripción de medicamentos por enfermeras en los Proyectos de Curso Pedagógico (PPC) del curso de Enfermería de Instituciones de Educación Superior en la red pública y privada de Campina Grande. -PB. Se propone un estudio cualitativo con enfoque descriptivo y documental. El estudio se realizó en la ciudad de Campina Grande-PB, en conjunto con instituciones de educación superior que tienen la carrera de Licenciatura en Enfermería en su matriz docente. La recogida se realizó a través de dos etapas operativas: análisis de todos los PPC, la segunda fue una entrevista semiestructurada, utilizando un guión previamente establecido y flexible con los coordinadores del curso. Los PPC de las instituciones investigadas no abordan contenidos / componentes curriculares para desarrollar en los estudiantes competencias para la prescripción de medicamentos y que las instituciones enfrentan desafíos para reajustar los proyectos pedagógicos tras la redemocratización de la educación. Es necesario que los coordinadores de cursos y profesores desarrollen medios para reajustar el PPC de acuerdo con lo que el SUS aboga por promover en los estudiantes una mirada crítica y reflexiva centrada en su campo de acción.

Palabras clave: Atención Primaria de Salud; Educación en enfermería; Prescripción de medicamentos por enfermeras.

\section{Introdução}

O enfermeiro assume o papel de protagonista dentro da Atenção Primária à Saúde (APS) no que se refere ao reconhecimento e as possibilidades de ações e planejamentos no processo saúde-doença. Em todo o mundo a enfermagem vem ganhando destaque e assumindo atribuições diferenciadas nos serviços de saúde, é uma profissão que se desenvolveu através dos tempos comprometida com a promoção, prevenção da saúde e o bem-estar físico e social dos indivíduos, família e coletividade (Backes et al., 2012).

Nesse novo cenário, abriu-se um espaço para que o enfermeiro exercesse práticas avançadas em saúde, sendo seu uso observado em vários países. Enfermeiro de Prática Avançada (EPA), ou Advanced Practice Nurse, termo internacionalmente adotado. Existem vários fatores que impulsionam a introdução do enfermeiro na prática incluindo a escassez de outros profissionais como os médicos, a inserção da tecnologia nos serviços de saúde, melhoria do acesso, aumento dos atendimentos e menor tempo de espera, a aceitação dos usuários, menor custo ao setor saúde (Buchan et al., 2013).

A prática avançada de enfermagem dá apoio para que o enfermeiro possa desenvolver sua autonomia profissional de forma independente, quatro modelos de enfermeiros prescritores de medicamentos foram apontados segundo o CIE: o independente, autônomo ou substitutivo; o dependente, colaborador, semiautônomo, complementar ou suplementar; o grupo protocolo e a prescrição alterando horário e dosagem (Buchan \& Calman, 2004). A prescrição de medicamentos por enfermeiros (PME) é considerada prática avançada da profissão a nível internacional de acordo com o levantamento realizado pelo International Council of Nurses (ICN).

No Brasil a Lei que assegura o ato da PME na Atenção Básica é a Lei do Exercício Profissional de Enfermagem, ${ }^{\circ}$ 7.498/86, regulamentada pelo Decreto $\mathrm{n}^{\circ}$ 94.406/1987, que determina que o enfermeiro exerça a prática prescritiva como membro da equipe, quando previamente estabelecida em programas de saúde pública. Os enfermeiros têm a autonomia para prescrever medicamentos e solicitar exames de acordo com os protocolos do Ministério da Saúde, na Atenção Primária à Saúde (APS), dentro da Estratégia de Saúde da Família (ESF), tendo como guia os Cadernos de Atenção Básica disponibilizados pelo Ministério da Saúde (Carneiro et al., 2008) e os protocolos recentemente publicados.

No constante a formação do enfermeiro para a PME, a DCN/ENF, não faz menção à PME, porém componentes curriculares como a farmacologia, a assistência e o ensino da enfermagem são disciplinas relacionadas à prática de prescrição 
que fazem parte dos currículos de enfermagem (CNE/CES, 2001). Competência define-se como a capacidade de utilização do conhecimento para a postura e o agir crítico para enfrentar as mais diversas situações. Porém, como cada situação é única, o exercício das competências exige uma mobilização cognitiva complexa, as competências são construídas durante o processo de formação (Perrenoud, 1999)

Em relação às Instituições de Ensino Superior (IES), o termo competência no contexto da formação também passou a ser inserido no Projeto Pedagógico de Curso (PPC). Cada IES é responsável pela construção do seu PPC, de acordo com as propostas estabelecidas pelas legislações vigentes. As IES adquiriram autonomia e responsabilidades, no que diz respeito ao PPC (Marçal et al., 2014). Considerando a importância do PPC como instrumento de concepção de ensino-aprendizagem e as matrizes curriculares a serem adotadas no processo do saber, tomou-se nesse estudo as seguintes questões de pesquisa: estão presentes no PPC dos cursos de graduação em enfermagem as competências e habilidades para a PME na Atenção Básica, consoantes o que define a Lei do Exercício Profissional e as normativas do Ministério da Saúde? Como os coordenadores dos cursos percebem essa questão?

Desse modo, o objetivo deste estudo é investigar a existência de previsão para desenvolvimento de competências para prescrição de medicamentos por enfermeiros nos Projetos Pedagógicos de Curso (PPC) do curso de Enfermagem das Instituições de Ensino Superior da rede pública e privada de Campina Grande- PB.

\section{Material e Métodos}

\section{Aspectos éticos}

A pesquisa seguiu os aspectos éticos previstos na Resolução 466/2012 do Conselho Nacional de Saúde, sendo aprovado pelo Comitê de Ética da Universidade Estadual da Paraíba. Para resguardar a identidade das IES, elas foram identificadas por letras do alfabeto na sequência em que foram pesquisadas.

Essa pesquisa contou com apoio financeiro da Universidade Estadual da Paraíba, por meio do Programa de Incentivo à Pós-graduação e Pesquisa (PROPESQ).

\section{Tipo de estudo}

Tratou-se um Estudo de Caso (Yin, 2001), com utilização de diferentes técnicas de coleta de dados, como Análise Documental e entrevista semiestruturada com informantes-chave. A análise Documental foi de cunho etnometodológico que compreende os documentos como uma versão particular do contexto em que ocorre o fenômeno construído com objetivos específicos (Garfinkel, 1984). Os documentos foram analisados como dispositivos comunicativos e não como compartimento de informação (Flick, 2009).

\section{Local da pesquisa}

O cenário da pesquisa foram as Instituições de Ensino Superior públicas e privadas, localizadas na cidade Campina Grande - Paraíba, que oferecem o curso de graduação em enfermagem. Atualmente a cidade conta com cinco IES que oferecem o curso de Enfermagem, sendo duas instituições públicas e três privadas.

Estabeleceram-se como critério de inclusão as IES que estivessem com oferta de curso de graduação em enfermagem, em pleno funcionamento, com turmas formadas. Não houve critérios de exclusão. Esse estudo envolveu quatro das cinco instituições, uma vez que não se obteve autorização para a realização da pesquisa em uma delas.

O corpus do estudo foi composto pelos PPCs das quatro IES e das entrevistas com os respectivos coordenadores dos cursos de enfermagem, tomados como informantes-chave para elucidar alguns pontos necessários à compreensão do estudo documental. 
Os documentos foram acessados nas IES pesquisadas considerando que apenas duas das IES dispõem seu PPC na internet para acesso. De posse dos documentos foi utilizado um roteiro previamente estabelecido para a coleta de dados, direcionado ao objetivo da pesquisa. O roteiro utilizado para a coleta de dados no PPC compreendeu questões relacionadas ao desenvolvimento de competência e habilidades para a prescrição de medicamentos da $\mathrm{AB}$.

\section{Coleta de dados e entrevistas}

Para proceder à coleta de dados para o estudo documental, foi solicitada de cada coordenador de curso a disponibilização do PPC do curso. Foram investigados os seguintes aspectos: o contexto da prescrição medicamentosa por enfermeiros no PPC se existia ou não; os componentes curriculares, as ementas e os conteúdos contemplados nos componentes disciplinares; bibliografia utilizada para subsidiar os componentes disciplinares, se havia ou não a indicação da utilização dos protocolos do Ministério da Saúde e dos Cadernos de Atenção Básica, como integrante do acervo recomendado.

Para a realização da entrevista com os coordenadores do curso de enfermagem, foi solicitado e agendado previamente como os profissionais um horário conveniente para a sua realização.

As entrevistas foram gravadas duplamente por meio de gravador digital. Foi realizada em ambiente livre de ruído e com garantia de privacidade das informações coletadas. As categorias analíticas previamente definidas foram: Dimensão (1) A percepção dos coordenadores do Curso de enfermagem sobre a PME: Categoria 1- Conhecimento da Lei do exercício Profissional; Categoria 2 - conhecimento sobre as legislações que tratam da PME; Categoria 3 - Conhecimento de instrumentos que norteiam a prática prescritiva do enfermeiro. Dimensão (2) Marcas da prescrição de medicamentos no PPC: Categoria 1 projeto Pedagógico do Curso e coerência quanto à PME; Categoria 2 - Disciplinas em que a PME é abordada no PPC; Categoria 3 - Formação do enfermeiro prescritor e a matriz curricular ofertada; Categoria 4 - Necessidade de uma base teórica que qualifique adequadamente o aluno como prescritor; Categoria 5 - Percepção dos coordenadores acerca da preparação do aluno para PME. As entrevistas foram transcritas na íntegra e constituíram o corpus que foi submetido à análise.

Após a transcrição das entrevistas, estas foram analisadas seguindo as fases: (1) Pré-análise (leitura flutuante das transcrições dos depoimentos); (2) Exploração do material (busca pelas semelhanças e contradições dos depoimentos); (3) Tratamento dos resultados (construção das categorias) e (4) Interpretação (reflexão crítica dos resultados) (Bardin, 2011). Dos depoimentos emergiram duas dimensões, sendo a primeira dimensão com três categorias e a segunda com cinco categorias empíricas que compõe os resultados desta pesquisa, a seguir apresentadas.

\section{Resultados e Discussão}

Os resultados foram organizados em três partes distintas: Caracterização das IES pesquisadas; Análise dos PPC das IES e a Percepção dos coordenadores do Curso de Enfermagem sobre a PME.

\section{Caracterização da IES pesquisadas}

Inicialmente buscou-se caracterizar as IES pesquisadas quanto ao funcionamento do curso, à estrutura curricular e os cenários de prática, como está disposto no Quadro 1. 
Quadro 1 - Caracterização das IES pesquisadas.

\begin{tabular}{|c|c|c|c|c|}
\hline Caracterização das IES & A & $\mathrm{B}$ & $\mathrm{C}$ & $\mathrm{D}$ \\
\hline \multicolumn{5}{|c|}{ Quanto ao funcionamento do Curso } \\
\hline $\begin{array}{c}\text { Credenciamento junto ao } \\
\text { MEC }\end{array}$ & Faculdade & Centro universitário & Universidade & Universidade \\
\hline Ano de Autorização & 2005 & 2007 & 2009 & 1974 \\
\hline Início das atividades & 2006 & 2006 & 2008.2 & $04 / 03 / 1974$ \\
\hline Ano de reconhecimento & 2010 & 2010 & 2012 & 1978 \\
\hline \multicolumn{5}{|c|}{ Quanto à Estrutura Curricular dos Cursos } \\
\hline Elaboração do PPC & NDE & NDE & Docentes /colegiado & NDE/Colegiado \\
\hline Atualização do PPC & 2018 & 2017 & 2018 & 2016 \\
\hline Predominância da formação & $\begin{array}{l}\text { Atenção hospitalar } \\
\text { /especializada }\end{array}$ & $\begin{array}{l}\text { Atenção hospitalar } \\
\text { /especializada }\end{array}$ & Saúde Pública & Saúde Pública \\
\hline Carga horária & 4.800horas & 4.000 & 4.170 & 4.210 \\
\hline $\begin{array}{l}\text { Previsão do ensino da } \mathrm{AB} \text { no } \\
\text { PPC }\end{array}$ & Sim & Sim & Sim & Sim \\
\hline $\begin{array}{l}\text { Utilização dos } \\
\text { Protocolos/Cadernos da AB }\end{array}$ & Sim & Sim & Sim & Sim \\
\hline \multicolumn{5}{|c|}{ Quanto aos cenários de práticas } \\
\hline $\begin{array}{l}\text { Condução das } \text { Atividades } \\
\text { Práticas }\end{array}$ & $\begin{array}{l}\text { Os docentes do } \\
\text { curso/Preceptores } \\
\text { contratados para este fim }\end{array}$ & $\begin{array}{l}\text { Preceptores contratados } \\
\text { para este fim }\end{array}$ & Os docentes do curso & $\begin{array}{l}\text { Os docentes do } \\
\text { curso }\end{array}$ \\
\hline $\begin{array}{l}\text { Atividades realizadas no } \\
\text { Campo }\end{array}$ & $\begin{array}{l}\text { Todas as que estiverem } \\
\text { disponíveis na Unidade. }\end{array}$ & $\begin{array}{l}\text { Puericultura, hiperdia, } \\
\text { pré-natal, educação em } \\
\text { saúde. }\end{array}$ & $\begin{array}{l}\text { Acolhimento, PTS, } \\
\text { territorialização, } \\
\text { mapeamento, conhecimento } \\
\text { dos programas vigentes, } \\
\text { assistência a diferentes } \\
\text { clientelas. }\end{array}$ & $\begin{array}{l}\text { Ações que estão } \\
\text { preconizadas na } \\
\text { prevenção, } \\
\text { promoção, tudo } \\
\text { que está no } \\
\text { Caderno da } \mathrm{AB} .\end{array}$ \\
\hline
\end{tabular}

Fonte: Dados da pesquisa documental (2018).

Os dados revelam que quanto ao cadastramento das IES no MEC verificou-se que uma IES é credenciada como faculdade, uma como Centro Universitário e duas instituições são consideradas Universidades (Quadro 1). O tempo de credenciamento junto ao MEC varia muito entre elas, sendo a mais antiga credenciada há mais de 44 anos e a mais recente há nove anos. Todas alcançaram reconhecimento de seus cursos.

A política neoliberal favoreceu a expansão dos cursos de graduação em enfermagem, esse novo modelo econômico do país ganhou força a partir da década de 1990, com isso cresceu a oferta de cursos e vagas em IES (Missio; Lopes e Renovato, (2011).

A autonomia pedagógica, administrativa e de gestão financeira das IES alcançada pela LDB de 1996, levou a democratização do ensino e aumentou o acesso ao ensino superior, a ampliação do número de vagas e cursos e por sua vez uma demanda maior de profissionais graduados no mercado de trabalho (Silva et al., 2012). No entanto, o que se tem observado com a expansão dos cursos é que a formação dos profissionais pode estar ocorrendo sem estreita relação das políticas públicas de saúde em relação à qualidade do ensino de acordo com o que preconiza o SUS (Higashi et al., 2017).

No que diz respeito à estrutura curricular dos cursos, observou-se que todas elas tiveram seus PPCs atualizados recentemente, com elaboração realizada, em sua maioria pelo Núcleo Docente Estruturante (NDE), que é um grupo de docentes, com atribuições acadêmicas de acompanhamento, consolidação e contínua atualização do Projeto Pedagógico. Cada instituição de ensino é responsável pelo planejamento curricular e pelo caminho que seus estudantes percorrerão até a sua formação 
profissional. É nesse momento da construção do PPC e matriz curricular onde ocorre o planejamento curricular e são envolvidos as leis e as diretrizes para a formação profissional, a experiências e a intenção docente, as características dos discentes e a realidade em que o curso está inserido (Regis \& Batista, 2015).

Quanto à predominância da formação entre área hospitalar e Saúde Pública, foi identificado que duas IES concentram sua formação na atenção hospitalar especializada e duas na atenção à Saúde Pública. Observa-se que mesmo que tenham ocorrido mudanças comas DCNS, o modelo flexneriano ainda se faz presente nos cursos de graduação da área da saúde e na prática dos serviços de atenção à saúde, o modelo hospitalocêntrico, centrado na doença (Marçal et al., 2014). Em lugar disso, a formação do enfermeiro deve ser paritária, ao se pensar que o processo ensino aprendizagem deveria extrapolar o domínio técnico cientifico da profissão, não pode ter como ponto de partida apenas a doença, o processo diagnóstico e o tratamento, deve - se promover uma visão ampliada de saúde, em uma dimensão de ações voltadas para o atendimento integral. Há necessidade da construção de conhecimentos múltiplos considerando a diversidade, a imprevisibilidade a subjetividade do ser humano a ser cuidado e do serviço o qual o profissional está inserido (Silva \& Sena, 2007).

Quanto à previsão do ensino da $\mathrm{AB}$ no $\mathrm{PPC}$ todos os coordenadores afirmaram que a $\mathrm{AB}$ fazia parte do rol de conteúdos discutidos no processo de formação, destacando o uso dos Protocolos e Cadernos de Atenção Básica do MS como instrumentos utilizados para nortear os docentes na condução das aulas. Assim, a abordagem dos conteúdos que envolvem a Atenção Básica dentro da matriz curricular dos cursos de enfermagem nas IES é uma realidade da maioria das instituições investigadas, visto que a $\mathrm{AB}$ é o primeiro nível de atenção em saúde e se caracteriza por um conjunto de ações que envolvem a promoção, proteção da saúde, prevenção dos agravos, diagnóstico e manutenção da saúde, no âmbito individual e coletivo (Brasil, 2017).

No cenário das práticas, a maioria dos docentes da própria Instituição ministra a disciplina e também acompanham os alunos nos estágios da AB. Em apenas uma Instituição preceptores são contratados para este fim. Quanto às atividades desenvolvidas pelos alunos nos cenários de prática da $\mathrm{AB}$ observa-se que todas as Instituições preveem que seus alunos alcancem a magnitude das ações que são oferecidas no campo, chamando a atenção para o desenvolvimento de competências que vão desde a organização e estrutura do processo de trabalho como mapeamento e territorialização até consultas nas linhas de cuidado estratégicas conforme orienta o MS.

As práticas desenvolvidas pelos alunos no contexto dos estágios na $\mathrm{AB}$ atendem as necessidades para uma formação que possibilita a aproximação de forma contínua com o mundo do trabalho. A relevância dessas experiências se justifica pela vivência pedagógica enriquecedora, com características inovadoras e peculiares, que possibilita o desenvolvimento de competências que possam ser aplicadas em outras realidades (Hemida, Barbosa \& Heidmann, 2015)

\section{Análise dos PPC das IES pesquisadas}

O Projeto Pedagógico de Curso de uma instituição é o documento que objetiva abordar tudo que envolve a formação do estudante como habilidades, competências, perfil do estudante (Marçal et al., 2014). Dos PPC analisados dois não mencionaram a PM e dois mencionaram no contexto das competências:

Campo de atuação profissional: De acordo com a Lei Federal $n^{\circ}$. 7.498, de 25/06/86, posteriormente, regulamentada pelo Decreto $n^{\circ}$. 94.406, de 08/06/87, que trata do exercício profissional de Enfermagem: [...]. Como integrante da equipe de saúde: participa no planejamento, execução e avaliação da programação de saúde; participa na elaboração, execução e avaliação dos planos assistenciais de saúde; realiza prescrição de medicamentos estabelecidos em programas de saúde pública e em rotina aprovado pelos protocolos do Ministério da Saúde. 
Por outro lado, os outros dois PPC analisados, não mencionaram a prescrição de medicamentos por enfermeiros. Observou-se ainda que foram justamente as IES A e B que os coordenadores afirmaram ter como predominância da formação na atenção hospitalar especializada, como revelou o quadro1. Esse achado sugere uma inclinação do PPC ao modelo biologicista, marcas transferidas ao longo dos anos com enfoque em especialização, priorizando uma prática operacional centrada no ambiente hospitalar, visando a cura do paciente, oriunda do modelo biomédico (Costa \& Miranda, 2009).

De modo contraditório, ao longo dos PPC analisados não foram observados componentes curriculares/ementas/conteúdo específicos que abordam a PME em nenhum dos PPC examinados. Esse achado corrobora com o estudo que identificou ausência do conteúdo específico PME especialmente no componente curricular de Farmacologia de uma universidade pesquisada (Marcolino, 2012). Um dos motivos para os enfermeiros não prescreverem é a falta de reordenação na formação para a qualificação da prática prescritiva, sendo essa uma responsabilidade das IES e dos Conselhos de Enfermagem, como observados em alguns países onde essa prática é bem-sucedida (Martiniano et al., 2016)

Os protocolos ministeriais que normatizam a PME foram citados em um PPC no componente curricular Processo de Cuidar em Saúde da Mulher I, os Protocolos da Atenção à Saúde Mulher, Cálculos Matemáticos aplicados na Dosagem de Fármacos Medicações presentes nos protocolos no componente curricular de Farmacologia Aplicada a Enfermagem, Protocolos Assistenciais da AB, na disciplina de Processo de Cuidar em Saúde Coletiva II, Protocolos Assistenciais na Saúde do Adulto em Processo do Cuidar em Saúde do Adulto I. Os demais PPC não mencionaram os protocolos. Tais protocolos têm como vantagens aproximar a prática dos melhores padrões recomendados para situações específicas, diminuição da variabilidade (padronização), diminuição de erros e redução de custos com insumos e materiais, pois haverá uma padronização para determinado procedimento. Os protocolos também melhoram a atuação dos profissionais por apresentar uma descrição das condutas e como devem ser realizadas que irá impactar nos processos de atendimento, na prevenção e hábitos de prescrição (Vieira et al., 2016)

\section{Dimensão 1- A percepção dos coordenadores do Curso de Enfermagem sobre a PME \\ Categoria 1 - Conhecimento da Lei do Exercício Profissional}

Quanto ao conhecimento dos coordenadores acerca da Lei do Exercício profissional, os coordenadores afirmam conhecê-la, porém não lembram ou não sabem citar o número da Lei, de acordo com os depoimentos:

Conheço. (C1). Sim, a gente tem conhecimento, eu não sei lhe citar qual o número da Lei e tudo mais, mas a gente sabe que nossa profissão é regida pela Lei do exercício profissional. (C2). Sim, descrever é? Dizer qual o número? Não lembro. (C3). Conheço, mas não lembro o número. (C4).

A Lei do Exercício Profissional constitui a base imprescindível para a prática da enfermagem. Os profissionais acobertados por essa Lei devem conhecê-la para fazer uma análise crítica e reflexiva sobre os limites, possibilidades, a ausência de normatização de atuação da categoria relativa a quaisquer assuntos (Oguisso \& Freitas, 2007).

O desconhecimento da legislação pode levar a uma fragmentação da formação, o saber do profissional ficará limitado a sua prática de atuação, sem possibilidade de ampliar novos conhecimentos. Para Trevisan et al. (2013) esperou-se que as Instituições formadoras acompanhassem a mudança que ocorreu a partir dos anos 2000 no campo da educação em saúde com uma visão crítica, e construtivista dos diferentes saberes, operando-se contrário ao modelo biologicistas e as posições conservadoras.

Segundo Oliveira; Lima e Baluta (2014) o conhecimento fragmentado, a inclinação pela formação prática teve repercussões nos próprios alunos refletindo ao longo dos anos, dificilmente se discutiam assuntos que não tivessem resultados 
imediatos, assuntos relacionados a princípios e diretrizes que fundamentariam a prática profissional eram sempre deixados de lado favorecendo a alienação profissional.

\section{Categoria 2 - Conhecimento sobre as legislações que tratam da PME}

Ao serem indagados se tem conhecimentos acerca da legislação que preveem a PME a maioria diz ter conhecimento, mas confundem a legislação com instrumentos, como protocolos e ainda é verificada certa confusão no entendimento da Legislação do Exercício Profissional com portarias instituídas nos municípios, como ser verificado na fala que se segue:

Eu conheço, tenho leitura sobre o protocolo, mas não sei a Lei porque não é da minha prática no dia a dia. (C1).

Os currículos ainda são construídos com foco nos conteúdos e não por competências, os docentes ficam presos a conteúdos e teorias repetidas, conceitos sem nenhuma reflexão entre teórico e prático. Muitas das vezes, os professores agem reproduzindo modelos históricos considerados como ideal, que não estimulam em seus alunos a prática da reflexão do meio que os cercam, ou seja, ensinam como foram ensinados (Alves et al., 2017).

Sim, sei que geralmente quem institui essas legislações próprias são os próprios municípios, há alguns municípios principalmente $n a A B$ que criam legislações que autorizam os enfermeiros a prescrever determinados medicamentos que são próprios da atenção básica e do processo de trabalho que eles estão inseridos, então assim eu tenho conhecimento que em alguns municípios essa prática já é adotada. (C2). Sim, eu sei que tem agora saber qual é e qual portaria foi dada, não tenho noção não, não sei qual é, eu sei que existe essa Lei. (C4).

Um dos participantes afirmou não ter conhecimento sobre a legislação que trata da PME, e assim revelou:

Não, não sei qual é. (C3).

Diferenças existentes entre as exigências das ações práticas de enfermagem no mercado de trabalho e daquelas implementadas na formação tem causado dificuldades na atuação profissional. Essas dificuldades podem estar relacionadas pelo descompasso nas salas de aula com o que se vê no dia a dia (Reibnitz et al., 2016). Por outro lado, também se percebe um descompromisso da categoria no que se refere à apropriação do seu campo de atuação.

Para Rodrigues; Mantovani e Zagonel (2007) os autores envolvidos no processo de formação ainda estão perdidos no processo de reorientação da formação, entende-se que a prática que o docente em sala de aula é determinante para a formação profissional, o que fica evidente que não depende só de um currículo bem estruturado, o que pode estar acontecendo é uma omissão de conteúdo, insegurança, conformismo e falta de compromisso dos docentes.

\section{Categoria 3 - Conhecimento de Instrumentos que norteiam a prática prescritiva do enfermeiro}

No que diz respeito ao conhecimento dos instrumentos que norteiam a prática da PME os coordenadores tinham percepções diferenciadas como pode ser verificado na fala que se segue:

Os protocolos da Atenção Básica eles são individualizados pelos municípios é o próprio município que determina quais os medicamentos podem ser prescritos, por exemplo: é [...] na saúde da criança o que eu posso tá prescrevendo para 
aquela criança e assim por diante são medicamentos já pré-existente dentro do próprio programa que o município autoriza que o enfermeiro tenha uma certa autonomia. (C2).

O conhecimento do profissional enfermeiro acercada prática da PM através dos protocolos pode evitar a atuação errônea por parte do enfermeiro o que acarretaria prejuízos de natureza física ou moral ao usuário e quando fosse comprovada culpa a obrigação de reparação de danos (Brasil, 1986).

A concepção de autonomia que o coordenador menciona remete ao fato de o enfermeiro assumir papel de destaque dentro de uma UBSF, sua atuação junto a uma equipe multidisciplinar. No contexto da PME os protocolos são direcionados a programas e prevê um cuidado integral, quando existe adesão dos protocolos pelo gestor local, o enfermeiro terá a autonomia de prescrever uma medicação após uma consulta de enfermagem caso o usuário necessite (Camboim et al., 2017).

Um estudo realizado por Medeiros e Peres (2011) identificou que grande parte dos alunos dos últimos períodos do curso de enfermagem tem buscado outras oportunidades de aprendizado além das atividades curriculares ofertadas na graduação, demonstrado pelo número de discentes que procuram estágios voluntários e remunerados, algumas dessas oportunidades são procuradas pela necessidade do acadêmico se aprimorar em técnicas e habilidades que consideram ser lacunas durante a graduação. $\mathrm{O}$ mesmo estudo revelou uma informação preocupante que durante estágio na $\mathrm{AB}$ dois discentes relataram não ter realizado nenhuma consulta de enfermagem. Destaca-se que esse dado levanta o questionamento sobre os motivos pelo qual os alunos sentem a necessidade da busca por capacitação, uma justificativa pode ser o distanciamento da instituição entre teoria e prática.

Essa fala também nos remete para uma formação no modelo biologicista:

Instrumentos como? Não, eu não sei dizer, porque eu não estou bem voltada para Atenção Básica. (C3).

Para estimular uma visão crítica e reflexiva acerca da prática profissional e o envolvimento desta no contexto social, componentes curriculares como a saúde coletiva e ciências sociais promovem o saber mais amplo, pois tem interconexão com outras subáreas (Regis e Batista, 2015).

Foi identificada pelo depoimento de um dos participantes a falta de conhecimento:

No caso aí a gente tem o SUS que dá direito que o enfermeiro prescreva na Atenção Básica. (C4).

\section{Dimensão 2 - Marcas da prescrição de medicamentos no PPC}

\section{Categoria 1 - Projeto Pedagógico do Curso e coerência quanto à PME}

Ao relatarem sobre a inserção do conteúdo PME no PPC, dois coordenadores afirmam à ausência de conteúdo específicos relacionados à PME nos seus PPC:

Não, prescrição de medicamentos não. (C3). Não, nesse de 2013 não, os que eu estou elaborando sim. (C4).

A ausência de conteúdo específicos acerca da PME nos PPC pode ocasionar um despreparo dos profissionais, e os serviços de saúde cada dia mais necessita de trabalhadores com visão ampliada do seu campo de atuação. Para Machado e Dal Poz (2015) o desenvolvimento de trabalhadores de saúde capacitados e motivados para superar os desafios é imprescindível. A força de trabalho na saúde brasileira passa por imensos desafios, os gestores em saúde têm tentado solucionar os desequilíbrios, no que tange as demandas por serviços com qualidade e eficiência. 


\section{Categoria 2 - Disciplinas em que a PME é abordada no PPC}

É observado a associação da PME, a Atenção Básica e os Programas de Políticas Públicas quando questionados em quais disciplinas a PME são abordadas:

Como conteúdo geral dentro da Atenção Primária à Saúde, nos programas de políticas. (C1).

Farmacologia, saúde coletiva, Saúde da Criança, Saúde da Mulher e Saúde do idoso foram apontados como disciplinas nas quais conteúdos de PME são contemplados, como se vê nos depoimentos a seguir:

Nas disciplinas de semiologia, de farmacologia, de saúde coletiva ela que carrega principalmente esse protocolo da própria atenção básica para difundir a autonomia do enfermeiro principalmente na Atenção Primária. (C2).

Só em farmacologia, de forma geral, a prescrição eles veem de forma geral quando eles estão vendo a parte da disciplina de gestão da Atenção Básica nos estágios eles mostram, mas de prescrição de medicação pela enfermagem não. (C3).

Olha, as disciplinas que a gente tem que consegue vê isso é saúde coletiva I e II, aí tem saúde da criança, da mulher, do idoso que também fala sobre prescrição de medicamentos, dado pelo enfermeiro, então ela é boa, mas não tem nenhuma disciplina voltada ainda específica para prescrição de medicamentos, vai ter nesse agora dentro da consulta de enfermagem. (C4).

Diante das falas pode ser observado que os coordenadores afirmam existir disciplinas em que a temática da PME é abordada, porém na análise documental dos seus PPC, matriz curricular não foi identificada nenhuma abordagem em relação a PME.

De acordo com Ximenes Neto et al. (2007) as disciplinas de Farmacologia, Deontologia e Ética são disciplinas em que a temática da PME deve ser incluída ou reforçada dentro dos currículos de graduação, por isso sugere uma maior carga horária, para que possa oferecer um melhor embasamento e conhecimento da prática profissional.

\section{Categoria 3 - Formação do Enfermeiro Prescrito e a Matriz curricular ofertada}

Ao relatarem sobre a formação do enfermeiro e a Matriz Curricular observou-se que houve consenso dos entrevistados quanto à ausência de conteúdo específicos:

Acho muito pouco, o conteúdo arcabouço teórico que nós temos. (C1). A gente considera um pouco fragilizada (C2). É[...] está atualizando a matriz no caso o PPC do curso, mas ainda entrando nessa questão da prescrição de medicamentos não, a gente está vendo outras disciplinas que tem que ser agregada aos poucos. (C3). Então ela é boa, mas não tem nenhuma disciplina voltada ainda especifica para prescrição de enfermagem, vai ter nesse agora dentro da consulta de enfermagem. (C4)

Os depoimentos mostram que os conteúdos que se referem à PME são abordados em outras disciplinas, mas não há nenhuma disciplina só voltada para a PME. Para Courtenay (2002), é essencial que o enfermeiro possua um conhecimento 
avançado para prescrever medicamentos, aspectos como a dosagem, os efeitos colaterais, a posologia, e todo o processo que envolva o ato prescritivo, que demanda o conhecimento detalhado dos fármacos.

\section{Categoria 4 - Necessidade de uma base teórica que qualifique adequadamente o aluno como prescritor}

Em relação à necessidade de oferta de componentes curriculares que ampliem o conhecimento e direcione para a prática de prescrição de medicamentos dois coordenadores julgaram necessária a inserção de uma base teórica que qualifique adequadamente o aluno como prescrito:

Precisaríamos melhorar o aporte de farmacologia, farmacocinética, farmacodinâmica, acho que é muito pouco o aporte... Então nesse sentido acho que a gente ainda não prepara o enfermeiro é[... Ipra exercer esse protocolo de forma muito efetiva a gente dá noções gerais aí talvez eu faça um link, talvez com alguma especialização, se nós quiséssemos encorpar a ideia de fazer com que o aluno já saísse com maturidade pra esse processo de prescrição protocolada, nós teríamos que investir muito mais na parte básica para que ele tivesse mais condições de avaliar clinicamente bem e prescrever a medicação hoje não percebo no PPC e que exista esse preparo seja suficiente para isso a gente dá noções gerais, é. (C1).

Os depoimentos acima mostram que os coordenadores avaliam seus PPC insuficientes para a prática prescritiva, mas que existe a proposta de inovação dos currículos com a inserção de conteúdos com mais enfoque para a PME. O enfrentamento a esses desafios requer uma reestruturação pedagógica, garantindo aos formandos que desenvolvam competências para atuar com autonomia e segurança da prática (Silva et al., 2010).

\section{Categoria 5 - Percepção dos coordenadores acerca da preparação do aluno para PME}

Quando indagados se os alunos saem da graduação preparados para PM, dois coordenadores relataram que não, um dos participantes mencionou que a carga horária é mínima para que seja trabalhado essa abordagem e que para isso precisaria focar na parte clínica:

Não, não. Justamente pelo que eu acabei de te falar eu acho que a nossa carga horária é mínima entendeu? Acho que se os professores não discutem medicações por que não é o foco da nossa assistência e mesmo que trabalhe com protocolo não se discute amplamente a parte clínica porque precisa ter, a prescrição não é só prescrever medicamento, a gente não prescreve medicamento puramente a gente prescreve medicamento baseado numa clínica, então precisaríamos focar nos componentes de trabalho, a parte clínica, a parte dos protocolos de saúde, na saúde coletiva precisaríamos voltar os nossos olhos pra parte clínica e isso hoje não é feito essa abordagem. (C1).

Na fala do coordenador observa-se que ainda existe a crença da visão de que a prescrição é núcleo privativo da categoria médica. Historicamente a prescrição de medicamentos pertenceu a categoria dos médicos passando a ser atribuição de diversos profissionais da área da saúde (Campos, 2000).

Não. A proposta tem né a mudança de forma geral, até porque a gente tem que estar dentro do padrão de todas as Instituições do padrão do MEC, a gente está passando pela renovação do MEC agora, é uma proposta, mas acontece que para a gente agora, agora não, a gente está fazendo essa reformulação, e colocando na cabeça dos alunos, inserido. 
Para Camboim et al., (2017) é importante que as IES tenham comprometimento em oferecer nas suas matrizes curriculares aportes para estudantes de enfermagem com conteúdo direcionados à prática da PME, base legal para tal prática é enfatizada na Portaria $n^{\circ} 1.625$ do Gabinete do Ministério (GM) do MS de 10 de junho de 2007 que oferece respaldo e possibilidade do Enfermeiro prescrever medicamentos de acordo com os protocolos do MS, destaca-se também Portaria ${ }^{\circ} 1.721$ de 15 de novembro de 1994 do Ministério da Educação e do Desporto que inclui a disciplina de farmacologia no currículo mínimo do curso de graduação e em enfermagem e a torna obrigatória no componente curricular.

\section{Considerações Finais}

Concluiu que as IES ainda enfrentam o desafio de adequar os seus Projetos Pedagógicos de Curso e matriz curricular para atender a essa demanda. Os quatro PPC analisados apresentaram déficits de conteúdo/componente curricular que abordassem a temática da PME, em dois PPC a abordagem deu-se apenas no contexto das competências, enquanto as outras duas não foi verificado em nenhum espaço do PPC. Os protocolos foram mencionados em uma IES em componentes curriculares. Percebe-se que a formação não vem desenvolvendo competências e habilidades para que os estudantes possam sair capacitados para prescrição de medicamentos. Por outro lado, os coordenadores percebem que há a necessidade de uma base teórica que fortaleça a prática do enfermeiro como prescritor e consideraram a matriz curricular ofertada por suas instituições insuficiente e fragilizada.

O grande desafio consiste em sensibilizar os docentes/coordenadores para a PME. Portanto, se faz necessário que os coordenadores dos cursos e os docentes desenvolvam meios para readequação do PPC de acordo com o que preconiza o SUS para promover nos alunos uma visão crítica e reflexiva voltada para o seu campo de atuação, e como a PME é atributo do enfermeiro, que as instituições forneçam conhecimento científico para atuação do enfermeiro como prescritor com base na legislação do exercício profissional da enfermagem e conteúdos teórico-práticos.

Perante a importância da PME no contexto da Atenção Primária à Saúde, sugerem-se pesquisas futuras que busquem evidenciar a percepção dos egressos dos cursos de enfermagem que estejam atuando na APS sobre a necessidade da abordagem da prescrição de medicamentos por enfermeiros na formação.

\section{Referências}

Alves, G. A., Martins, A. C., Pinho, S. E., Almeida, M. A. N. \& Tobias, C. G. (2017). Prática docente do enfermeiro na rede cegonha à luz da teoria históricocultural. Revenferm UFPE (on-line), 11(9), 3330-7.

Bardin, L. (2011). Análise de Conteúdo. Ed. Revisada e ampliada. Edições, 70 p.

Bakes, D. S., Bakes, M. S., Erdman, A. L., \& Buscher, Andreas. O papel profissional do enfermeiro no Sistema Único de Saúde? Da saúde comunitária à estratégia de saúde da família. Ciência \& Saúde Coletiva, 17(1):223-230, 2012

Brasil. (1986). Lei $n$. 7.498, de 25 de junho de 1986. Dispõe sobre a regulamentação do exercício da enfermagem e dá outras providências. Diário Oficial [da] união. 1986 jun. 26, Seção 1. P. 1

Buchan, J. \& Calman, L. (2004). Skill Mix and Policy Change in the Health Workforce: Nurses in Andvanced Roles. OECD Working Papers, 17.

Camboim, A. C. J., Souza, A. N. M., Lima, B. C., Silva, L. C. M., Silva, M. N. A. \& Camboim, F. E. F. (2017). Prescrição de medicamentos por enfermeiros: legalidade, prática e benefícios. Revista Recien, 7 (19), 15-27.

Campos, G. W. S. (2000). Um método para a análise e co-gestão de coletivos: a constituição do sujeito, a produção de valor de uso e a democracia em instituições: O Método da roda. Hucitec.

Courtenay, M. (2002). Educationand nurse prescribing. Nursing Times, 98(9).

Conselho Nacional de Educação/ Câmara de Ensino Superior (CNE/CES). (2001). Parecer 1133, 7 ago 2001. Homologado. Despacho do Ministro em 01/10/2001, Diário Oficial da União (DOU), Brasília, 3 de outubro de 2001, Seção IE, p. 131.

Costa, S. K. R. \& Miranda, N. A. F. (2009) Sistema único de saúde e da família na formação acadêmica do enfermeiro. Revista Brasileira de Enfermagem.

Flick, U. (2009) Introdução à pesquisa qualitativa. Tradução de Joice Elias Costa. Artmed. 
Garfinkel, H. (1984). Studies in ethnomethodology. Polity Press.

Galavote, H. S., Zandonade, E., Garcia, A. C. P., Freitas, P. S. S., Seidl, H., Contarato, P. C., Andrade, M. A. C. \& Lima, R. C. D. (2016). O trabalho do enfermeiro na atenção primária à saúde. Escola Anna Nery, 20(1), 90-98

Hermida, V. M. P., Barbosa, S. S. \& Heidmann, B. S. T. I. (2015). Metodologia ativa de ensino na formação do enfermeiro: inovação na atenção básica. Revista de Enfermagem, 5 (4), 683-691

Higashi, C. D. G., Erdman, L. A., Andrade, R. S. \& Bettinelli, A. L. (2017). O contexto e as implicações das decisões colegiadas para a formação do enfermeiro. REME - Revista Min de Enfermagem.

Marçal, M., Marconisin, M., Xavier, J., Silveira, L., Alves, H. V. \& Lemos, A. (2014). Análise dos projetos pedagógicos de cursos de graduação em enfermagem. Revista Baiana de Enfermagem, 28(2), 117-125

Marcolino, C. E. (2012). Formação do enfermeiro para prescrição de medicamentos na atenção básica: estudo de caso. 2012. 36f. Trabalho de conclusão de Curso. Universidade Estadual da Paraíba, Campina Grande-PB.

Martiniano, S. C., Coêlho, A. A., Souza, B. M., Brandão, A. C. I., Silva, F. K. A. \& Uchôa, C. A. S. (2016). Caracterização da prescrição de medicamentos por enfermeiros nos protocolos de Atenção Primária à Saúde. Revista de enfermagem da UERJ, 24(3), e13923.

Medeiros, C. V. \& Peres, M. A. (2011) Atividades do enfermeiro no âmbito da atenção básica à saúde. Texto Contexto de Enfermagem, 20 (Esp), $27-35$.

Missio, L., Lopes, R. M. M. \& Renovato, D. R. (2011) Os reflexos da educação superior pós-LDB de 1996: um foco nos cursos de graduação em enfermagem. Educação e Fronteiras On-Line, 1(1), 80-91

Oguisso, T. \& Freitas, G. F. (2007). Enfermeiros prescrevendo medicamentos: possibilidades e perspectivas. Revista Brasileira de Enfermagem, 60(2), 141144.

Oliveira, M. C. M., Lima, L. T. \& Baluta, H. V. (2014). A formação do profissional enfermeiro, no contexto das reformas de ensino no Brasil. Revista Grifos, $36 / 37$.

Organização Mundial da Saúde - OMS (2018). Organização Pan-americana da Saúde. Ampliação do papel dos enfermeiros na atenção primária à saúde. Washinton, D.C. 2018. OMS. Organização mundial da saúde. http://www.who.int/about/es/.

Perrenoud, P. (200). 10 novas competências para ensinar convite a viagem. (1999). Artmed.

Reibnitz, S. K., Kloh, D., Corrêa, B. A., \& Lima, M. M. (2016). Reorientação da Formação do Enfermeiro: Análise a partir dos seus protagonistas. Revista Gaúcha de Enfermagem, 37(esp), e68457

Regis, G. C. \& Batista, A. N. (2015). O enfermeiro na área da saúde coletiva: concepções e competências. Revista Brasileira de Enfermagem, 68(5), 830-6

Rodrigues, J., Zagonel, S. P. I. \& Mantovani, F. M. (2007). Alternativas para a prática docente no ensino superior de enfermagem. Escola Anna Revista de Enfermagem, 11(2), 313-7

Silva, L. K., Sena, R. R., Silveira, R. M., Tavares, S. T. \& Silva, M. P. (2012). Desafios da formação do enfermeiro o contexto da expansão do ensino superior. Escola Anna Nery, 16(2), 380- 387

Silva, G. M., Fernandes, D. J., Teixeira, S. A. G. \& Silva, O. M. R. (2010) Processo de formação do enfermeiro na contemporaneidade: desafios e perspectivas. Texto Contexto Enfermagem, 19(1), 176-84.

Trevisan, D. D., Minzon, T. D. \& Testi, V. C. (2013). Formação de enfermeiros: distanciamento entre a graduação e a prática profissional. Ciência Cuidado e Saúde, 12(2), 331-337.

Vieira S. E. J. L., Silva F. C. A., Moreira R. A. G., Cavalcanti F. L., Silva M. R. Protocolos na atenção à saúde de mulheres em situação de violência sexual sob a ótica de profissionais de saúde. Ciência \& Saúde Coletiva, 21(12):3957-3965, 2016

Ximenes Neto, F. R. G., Costa, F. A. M., Chagas, M. I. O \& Cunha, I. C. K. O. (2007). Olhares dos enfermeiros acerca de seu processo de trabalho na prescrição medicamentosa na Estratégia Saúde da Família. Revista Brasileira de Enfermagem, 60(2), 133-140.

Yin, R. K. (2001). Estudos de caso: planejamento e métodos. Bookman. 